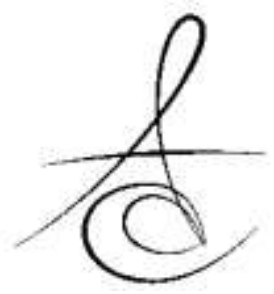

\title{
VAKUMLA ŞEKİLLENDİRİLEN ORTODONTİK PEKİŞTİRME APAREYLERİNİN KOMPOZITT RESTORASYONLARIN KLİNİK BAŞARISINA ETKİSİ
}

\section{THE EFFECT OF VACUUM-FORMED RETAINERS ON THE CLINICAL SUCCESS OF COMPOSITE RESTORATIONS}

\author{
Dr. Öğr. Üyesi Serdar AKARSU* \\ Dr. Sultan AKTUĞ KARADEMİR* \\ Doç. Dr. Süleyman Kutalmış BÜYÜK**
}

\author{
Makale Kodu/Article code: 4275 \\ Makale Gönderilme tarihi: 15.01 .2020 \\ Kabul Tarihi: 20.03.2020 \\ DOI: $10.17567 /$ ataunidfd.706727
}

Serdar Akarsu: ORCID ID: 0000-0002-7816-1635

Sultan Aktuğ Karademir: ORCID ID: 0000-0001-8604-5768

Süleyman Kutalmış Büyük: ORCID ID: 0000-0002-7885-9582

\section{öz}

Amaç: Anterior bölgede görülen diastemalar hem estetik hem de psikososyal problemlere neden olabilmektedir. Bu çalışmanın amacı üst anterior bölgedeki diastemaların kapatılmasında kullanılan direkt kompozit restorasyonların klinik başarısına vakumla şekillendirilen ortodontik pekiştirme apereylerinin etkisini değerlendirmektir.

Gereç ve Yöntem: Bu retrospektif çalışmaya ortodontik tedavi yapılmamış veya ortodontik tedavi sonrası anterior bölgede diastemaya sahip 40 hastadaki 92 restorasyon dahil edilmiştir. Restorasyonlar Clearfil Majesty ${ }^{\mathrm{TM}}$ ES-2 (Kuraray, Okoyama, Japonya) kullanılarak aynı hekim tarafından yapılmıștır. Hastalar, diastema kapaması sonrası vakumla şekillendirilen pekiştirme apareyi kullananlar (Grup 1: 20 hasta 45 restorasyon) ve kullanmayanlar (Grup 2: 20 hasta 47 restorasyon) olarak iki gruba ayrımışıı. Restorasyonlar 1 yıl sonra modifiye United States Public Health Service (USPHS) kriterleri kullanılarak değerlendirilmiştir. Veriler Ki-Kare testi kullanılarak değerlendirilmiştir.

Bulgular: Retansiyon, renk uyumu ve yüzey pürüzlülüğü açısından gruplar arasında istatistiksel olarak anlamlı bir fark bulunamamıştır $(p>0,05)$. Grup 1'de polisajla düzeltilemeyen, daha fazla kenar renklenmesi görülürken, Grup 2 de anatomik form kaybı Grup 1'e göre daha fazladır. Gruplar arasında kenar renklenmesi ve anatomik form açısından istatistiksel olarak anlamlı bir fark vardır $(\mathrm{p}<0,05)$.

Sonuç: Ortodontik tedavi sonrasında kullanılacak vakumla şekillendirilen pekiştirme apereyleri diastema kapamasında kullanılan direkt kompozit restorasyonların anatomik formunu korurken, restorasyon-diş sınırında kenar renklenmesine neden olabilmektedir. Bu nedenle ortodontik tedavi sonrasında pekiştirme apareyi kullanan hastaların oral hijyen konusunda bilinçlendirilmesi gerekmektedir.

Anahtar Kelimeler: Diastema, Kompozit restorasyon, Pekiştirme apareyi

\section{ABSTRACT}

Aim: Diastemas in the anterior region can cause both aesthetic and psychosocial problems. The aim of this study was to evaluate the effect of vacuum-formed orthodontic retainer on the clinical success of direct composite restorations used in the closure of diastemas.

Material and Methods: In this retrospective study, 92 restorations in 40 patients with diastema in the anterior region without orthodontic treatment or after orthodontic treatment were included. Restorations were performed by the same operator using Clearfil MajestyTM ES-2 (Kuraray, Okoyama, Japan). The patients was divided into two groups: Those using vacuum-formed orthodontic retainer after diastema closure (Group 1: 20 patients, 45 restorations) and those who did not using vacuum-formed orthodontic retainer after diastema closure (Group 2: 20 patients, 47 restorations). Restorations were evaluated using modified United States Public Health Service (USPHS) criteria. Data were analyzed using Chi-square test.

Results: No statistically significant difference was found between the groups in terms of retention, color matching and surface roughness $(p>0.05)$. In Group 1, there was more marginal discoloration which could not be corrected by polishing, whereas in Group 2, anatomic form loss was higher than in Group 1. There was a statistically significant difference between the groups in terms of marginal discoloration and anatomic form $(p<0.05)$.

Conclusion: Vacuum-formed orthodontic retainer appliances to be used after orthodontic treatment may maintain the anatomical form of direct composite restorations used in diastema closure and may cause marginal discoloration at the restoration-tooth interface. Therefore, patients after orthodontic treatment should be made conscious about oral hygiene.

Keywords: Diastema, Composite restoration, Vacuum- formed retainer

*Ordu Üniversitesi Diş Hekimliği Fakültesi Restoratif Diş Tedavisi Anabilim Dalı, Ordu

** Ordu Üniversitesi Diş Hekimliği Fakültesi Ortodonti Anabilim Dalı, Ordu

Kaynakça Bilgisi: Akarsu S, Aktuğ Karademir S, Büyük SK. Vakumla Şekillendirilen Ortodontik Pekiştirme Apareylerinin Kompozit Restorasyonların Klinik Başarııına Etkisi. Atatürk Üniv Diş Hek Fak Derg 2020; 30: 360-5.

Citation Information: Akarsu S, Aktug Karademir S, Buyuk SK. The Effect of Vacuum-Formed Retainers on The Clinical Success of Composite Restorations. J Dent Fac Atatürk Uni 2020; 30: 360-5. 


\section{GİRİŞ}

Toplumsal bilincin gelişmesiyle birlikte, diş hekimliği uygulamalarında doğal diş estetiğinin sağlanması, fonksiyon ve fonasyon kadar önem kazanmıştır. ${ }^{1}$ Geçmişte hastaların önceliği ağrı hissetmemek iken günümüzde bunun yerini estetik kaygılar almıştır. Özellikle anterior dişleri ilgilendiren renk, şekil, yapı ve konum bozuklukları hastalarda hem estetik hem de psikososyal problemlere neden olabilmektedir. Üst anterior dişler bölgesinde görülen diastemalar en sık görülen maloklüzyonlardan biridir ve insidansı çeşitli toplumlarda \%1,6 ile \%25,4 arasında değişmektedir. ${ }^{2}$

Genetik ve ırksal yatkınlık, gelişimsel kusurlar ve doğumsal anomaliler, lokal fiziksel engeller, kas dengesizliği, zararlı alışkanlıklar, bolton uyumsuzluğu veya diş anomalileri gibi birçok etyolojik faktöre bağlı olabilen anterior bölge diastemaları ${ }^{3}$; ortodontik, protetik ve restoratif olarak tedavi edilebilmektedir. ${ }^{4} \mathrm{Te}-$ davi süresinin uzun ve maliyetin yüksek olması nedeniyle protetik ve ortodontik tedavi seçenekleri yerine kompozit rezinlerin kullanıldığı konservatif restorasyonlar hastalar tarafından sıklıkla tercih edilmektedir. ${ }^{5}$

Son yıllarda estetik restoratif uygulamalarda kompozit rezinlerin kullanılması, adeziv sistemler ve kompozit rezin materyallerdeki gelişmelere bağlı olarak artmıştır. Kompozit rezin teknolojisindeki gelişmelere bağlı olarak materyalin estetik ve mekanik özelliklerini geliştirmek için kompozit rezinlerdeki doldurucular makropartiküllerden nanopartiküllere dönmüştür. ${ }^{6}$ Literatürde anterior bölgede diastema kapatılmasında direkt kompozit restorasyonların değerlendirildiği invivo çalışmalar olmasına karşın ${ }^{7,8}$ vakumla şekillendirilen ortodontik pekiştirme apareyinin anterior bölgedeki kompozit restorasyonların başarısı üzerine etkisini gösteren çalışmalar sınırlıdır.

$\mathrm{Bu}$ çalışmanın amacı ortodontik tedavi sonrası relapsı engellemek için kullanılan vakumla şekillendirilen pekiştirme apareyinin anterior bölgedeki diastemaların kapatılmasında kullanılan direkt kompozit restorasyonların klinik başarısına olan etkisini değerlendirmektir.

\section{GEREÇ VE YÖNTEM}

Bu çalışmaya Ordu Üniversitesi Diş Hekimliği Fakültesi Restoratif Diş Tedavisi Anabilim Dalı Kliniğine başvurmuş, ortodontik tedavi görmüş veya görmemiş, anterior bölge diastemaları direkt kompozit restorasyonlar ile kapatılmış 18-30 yaş arası bireyler arasından seçilerek, uygun kriterleri sağlayan hastalar dahil edilmiştir. Tüm prosedürler Helsinki Deklerasyonu ilkelerine uygun olarak gerçekleştirilmiştir. Bu retrospektif çalışmanın protokolü Ordu Üniversitesi Girişimsel Olan Klinik Araştırmalar Etik Kurulu tarafından değerlendirilmiştir ve kabul edilmiştir (2020-04). Diastema kapamasında maksiller santral ve lateral dişlerin minelerinin pürüzlendirmesi için \%37'lik ortofosforik asit 30 saniye uygulanmıştır. Otuz saniye sonra havasu spreyi ile yıkanarak uzaklaştırılmıştır. Şeffaf matriks bandı diş etinin altına girecek şekilde yerleştirildikten sonra asit uygulanmış diş yüzeylerine universal adeziv sistem olan Single Bond Universal (3M ESPE) üretici firma önerileri doğrultusunda total-etch olarak uygulanmıştır. Kompozit rezinin polimerizasyonu için LED ışık cihazı Elipar S10 (3M ESPE) kullanılmıştır. Daha sonra uygun renk kombinasyonlarındaki Clearfil MajestyTM ES-2 (Kuraray) kompozit rezin diş yüzeylerine uygulanarak polimerize edilmiştir. Restorasyonların bitim ve polisajı için Sof-Lex pop-on disk (3M, Dental Products) ve sarı kuşak bitirme frezleri (Diatech Dental) kullanılmıştır (Tablo 1). Anterior bölge diastemaları aynı hekim (S.A.) tarafından ve Clearfil Majesty $^{\mathrm{TM}}$ ES-2 (Kuraray) kullanılarak kapatılmış olan katılımcılar 2 gruba ayrılmıştır.

Tablo 1. Çalışmada kullanılan restoratif materyal, bitirme ve cila sistemleri

\begin{tabular}{|l|l|l|l|}
\hline & İçeriği & Üretici firma & $\begin{array}{l}\text { Batch } \\
\text { no }\end{array}$ \\
\hline $\begin{array}{l}\text { Clearfil } \\
\text { Majesty } \\
\text { ES-2 }\end{array}$ & $\begin{array}{l}\text { Bisfenol A diglisidilmetakrilat, } \\
\text { Silanlanmış baryum cam doldurucu, } \\
\text { Önceden polimerize edilmiş organik } \\
\text { doldurucu, Hidrofobik aromatik } \\
\text { dimetakrilat, Başlatıcılar, Inorganik } \\
\text { dolgu ağırlıkça\% 78, hacimce\% 40. }\end{array}$ & $\begin{array}{l}\text { Kuraray } \\
\text { Okoyama, } \\
\text { Japonya }\end{array}$ & 000049 \\
& Aliminyum oksit kaplı diskler & $\begin{array}{l}\text { 3M, Dental } \\
\text { Products } \\
\text { St.Paul,MN, } \\
\text { ABD }\end{array}$ & 2381 \\
$\begin{array}{l}\text { Soft-lex } \\
\text { sistemi }\end{array}$ & \multicolumn{1}{|c|}{$\begin{array}{l}\text { 3M, ESPE } \\
\text { Neuss, } \\
\text { Almanya }\end{array}$} & 611430 \\
\hline $\begin{array}{l}\text { Single } \\
\text { Bond } \\
\text { Universal }\end{array}$ & $\begin{array}{l}\text { MDP, fosfat monomer, dimetakrilat } \\
\text { rezinler, HEMA, metakrilat-modifiye } \\
\text { polialkenoik asit kopolimeri, } \\
\text { doldurucu, etanol, su, inisiyatör, silan }\end{array}$ & \\
\hline
\end{tabular}

1. Grup; Ortodontik tedavi görmüş olan hastalarda, diastema kapama sonrasında vakumla şekillendirilen termoplastik pekiştirme apareyi kullananlar (20 hastadaki 45 üst anterior diş) (Resim 1).

2. Grup; Ortodontik tedavi görmemiş olan hastalarda, diastema kapama sonrasında vakumla şekillendirilen termoplastik pekiştirme apareyi kullanmayanlar (20 hastadaki 47 üst anterior diş) (Resim 2). 


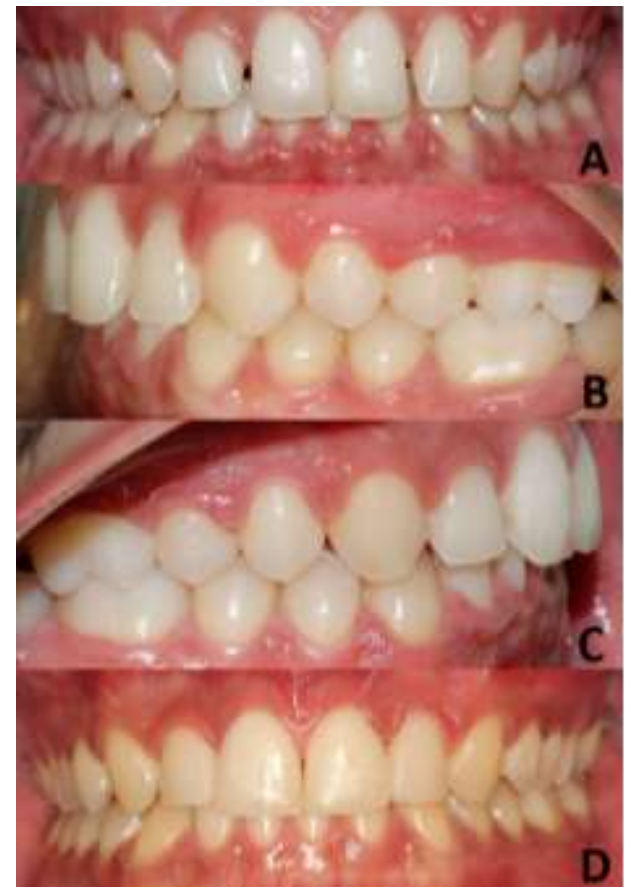

Resim 1. 1.Grupta (A: Başlangıçtaki görünüm; B: kompozit rezin ile restore edilmiş 21,22 nolu dişler; C: Kompozit rezin ile restore edilmiş 11,12 nolu dişler; $\mathrm{D}$ : 1 yıl sonraki görünüm)

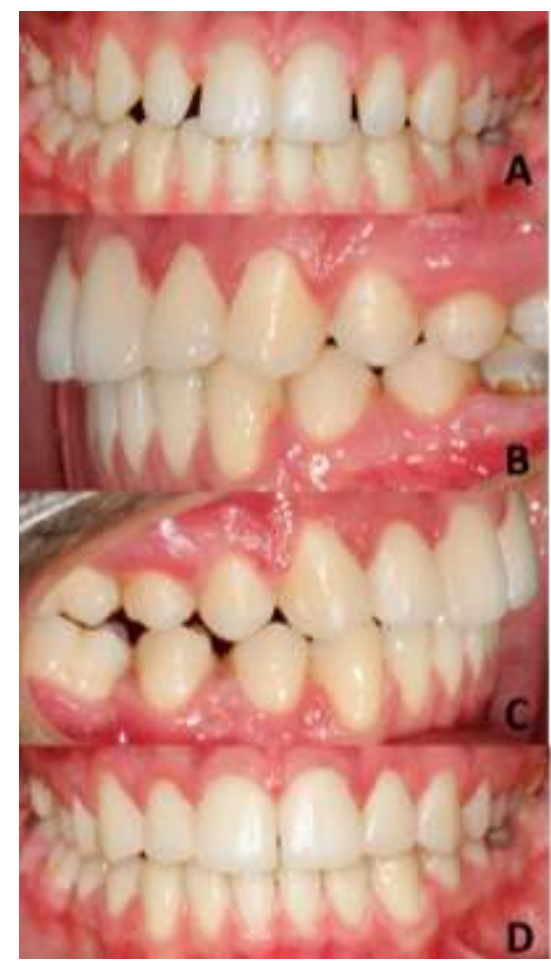

Resim 2. 2.Grupta (A: Başlangıçtaki görünüm; B: kompozit rezin ile restore edilmiş 21,22 nolu dişler; C: Kompozit rezin ile restore edilmiş 11,12 nolu dişler; D: 1 yıl sonraki görünüm)

Tablo 2. Diastema kapamasında kullanılan direkt kompozit restorasyonların değerlendirildiği modifiye USPHS kriterleri

\begin{tabular}{|c|c|c|c|}
\hline Kriterler & Alfa & Bravo & Charlie \\
\hline Retansiyon & $\begin{array}{c}\text { Restorasyonda } \\
\text { herhangi bir kayıp } \\
\text { yok }\end{array}$ & & $\begin{array}{c}\text { Restorasyon } \\
\text { tamamen ya da } \\
\text { kısmen kaybedilmiş }\end{array}$ \\
\hline$\frac{\frac{\text { Kenar }}{\text { renklen- }}}{\underline{\text { mesi }}}$ & $\begin{array}{l}\text { Restorasyon } \\
\text { sınırlarında } \\
\text { herhangi bir } \\
\text { renklenme yok }\end{array}$ & $\begin{array}{c}\text { Restorasyon } \\
\text { sınırlarında marjin } \\
\text { boyunca penetre } \\
\text { olmayan hafif bir } \\
\text { renklenme var. }\end{array}$ & \begin{tabular}{|c|} 
Restorasyon \\
sınırlarında polisaj ile \\
düzeltilemeyen ciddi \\
bir renklenme var.
\end{tabular} \\
\hline $\begin{array}{l}\text { Kenar } \\
\text { uyumu }\end{array}$ & \begin{tabular}{|c|} 
Restorasyon \\
sınırlarında sondla \\
hissedilen ya da \\
gözle görülebilen \\
bir aralanma yok
\end{tabular} & \begin{tabular}{|} 
Restorasyon \\
sınırlarında sondla \\
hissedilen ve gözle \\
görülebilen bir \\
aralanma var
\end{tabular} & $\begin{array}{c}\text { Restorasyon } \\
\text { sınırlarında dentin } \\
\text { dokusunu içeren } \\
\text { açıklık var }\end{array}$ \\
\hline $\begin{array}{l}\text { Renk } \\
\text { uyumu }\end{array}$ & \begin{tabular}{|c|} 
Restorasyonla diş \\
dokusu arasında \\
renk ve \\
translüsensi \\
açısından \\
uyumsuzluk yok
\end{tabular} & \begin{tabular}{|c|} 
Restorasyonun \\
rengi klinik olarak \\
kabul edilebilir \\
durumda
\end{tabular} & $\begin{array}{l}\text { Restorasyon diş } \\
\text { rengiyle tamamen } \\
\text { uyumsuz }\end{array}$ \\
\hline $\begin{array}{c}\text { Anatomik } \\
\text { form }\end{array}$ & $\begin{array}{c}\text { Restorasyon dişle } \\
\text { anatomik olarak } \\
\text { devam } \\
\text { göstermektedir. }\end{array}$ & $\begin{array}{l}\text { Restorasyonda hafif } \\
\text { madde kaybı vardır. } \\
\text { Ancak klinik olarak } \\
\text { kabul edilebilir } \\
\text { düzeydedir. }\end{array}$ & $\begin{array}{c}\text { Restorasyonda klinik } \\
\text { olarak kabul edilemez } \\
\text { düzeyde madde kayb } \\
\text { vardır }\end{array}$ \\
\hline $\begin{array}{l}\text { Yüzey } \\
\text { pürüzlü- } \\
\text { lüğü }\end{array}$ & \begin{tabular}{|c|} 
Restorasyon \\
yüzeyi ve çevre \\
mine dokusu aynı \\
pürüzlülüktedir.
\end{tabular} & $\begin{array}{c}\text { Restorasyon yüzeyi } \\
\text { mine dokusuna göre } \\
\text { daha fazla } \\
\text { pürüzlülüktedir. }\end{array}$ & $\begin{array}{c}\text { Restorasyon } \\
\text { yüzeyinde kırık } \\
\text { oluşmuştur. } \\
\text { Yenilenmesi } \\
\text { gerekmektedir. }\end{array}$ \\
\hline
\end{tabular}

Vakumla şekillendirilen termoplastik pekiştirme apereyi kullanan hastalar ilk 6 ay gece gündüz, ikinci 6 ay ise sadece gece uyurken apareylerini kullanmışlardır.

Çalışmaya dahil edilen dişlerin değerlendirilmesi restorasyonları yapan hekimden farklı bir diş hekimi (S.A.K.) tarafından modifiye USPHS kriterleri kullanılarak 1 yıl sonra gerçekleştirilmiştir (Tablo 2). Kompozit restorasyonlar anatomik form, kenar renklenmesi, renk uyumu, yüzey pürüzlülüğü, retansiyon açısından değerlendirilmiştir. İstatistiksel analizler SPSS (IBM Corp., Armonk, NY, USA) istatistik programı ile yapılmıştır. Verilerin istatistiksel analizi için Pearson Ki-Kare testi kullanılmıştır.

Tablo 3. Diestema kapamasında kullanılan kompozit restorasyonların 1 yıllık klinik takibi

\begin{tabular}{|c|c|c|c|c|c|c|c|c|c|c|c|c|c|c|}
\hline & \multicolumn{2}{|c|}{ Retansiyon } & \multicolumn{3}{|c|}{\begin{tabular}{l|} 
Kenar \\
renklenmesi
\end{tabular}} & \multicolumn{3}{|c|}{$\begin{array}{l}\text { Renk } \\
\text { uyumu }\end{array}$} & \multicolumn{3}{|c|}{$\begin{array}{l}\text { Anatomik } \\
\text { form }\end{array}$} & \multicolumn{3}{|c|}{$\begin{array}{l}\text { Yüzey } \\
\text { pürüzlülüğü }\end{array}$} \\
\hline & $a$ & C & $\mathrm{a}$ & $\mathrm{b}$ & $\mathrm{C}$ & $a$ & $\mathrm{~b}$ & $\mathrm{C}$ & $a$ & $\mathrm{~b}$ & C & $a$ & $\mathrm{~b}$ & $\mathrm{C}$ \\
\hline $\begin{array}{l}\text { Ortodontik } \\
\text { Plak } \\
\text { Kallanıyor }\end{array}$ & 42 & 3 & 25 & 8 & 9 & 39 & 3 & & 41 & 1 & 0 & 34 & 8 & 0 \\
\hline $\begin{array}{l}\text { Ortodontik } \\
\text { Plak } \\
\text { Kullanmıyor }\end{array}$ & 45 & 2 & 32 & 12 & 1 & 44 & 1 & & 36 & 8 & 1 & 36 & 9 & 0 \\
\hline P* & 0,61 & & 0,0 & & & 0,2 & & & 0,0 & & & & & \\
\hline
\end{tabular}




\section{BULGULAR}

Üst ön diş diastemaları Clearfil MajestyTM ES-2 ile restore edilmiş 40 bireyin 1 yll sonra modifiye USPHS kriterleri ile değerlendirilerek elde edilen bulguları Tablo 3'de sunulmuştur. Çalışmamızda vakumla şekillendirilen termoplastik pekiştirme apareyi kullanan 1. Grupta 3, ve vakumla şekillendirilen termoplastik pekiştirme apereyi kullanmayan 2. Grupta ise 2 restorasyonun total kaybı görülmüştür. 1. Grupta retansiyon oranı \%92,8 iken 2. Grupta \% 95,5'dir. Gruplar arasında istatistiksel olarak anlamlı bir fark yoktur $(p=0,610)$.

Restorasyonlar renk uyumu açısından değerlendirildiğinde 1. Grupta 3, 2. Grupta ise 1 dişte restorasyonla diş dokusu arasında renk açısından klinik olarak kabul edilebilir bir uyumsuzluk olduğu görülmüştür. İstatistiksel olarak anlamlı bir fark yoktur $(p>0,05)$.

Restorasyonlar yüzey pürüzlülüğü açısından değerlendirildiğinde 1. Grupta 8, 2. Grupta 9 dişte, restorasyon yüzeyinin mine dokusuna göre daha pürüzlü olduğu görülmüştür. Bu fark istatistiksel olarak anlamlı değildir ( $p>0,05)$.

Kenar renklenmesi açısından değerlendirildiğinde ise gruplar arasında istatistiksel bir fark vardır $(p=0,040)$. 1. Grupta 9 dişte Restorasyon sınırlarında marjin boyunca penetre olmuş, polisajla düzeltilemeyen renklenme olduğu 2. Grupta ise sadece 1 dişte marjin boyunca penetre olmuş polisajla düzeltilemeyen renklenme olduğu görülmüştür.

Anatomik form açısından değerlendirildiğinde de gruplar arasında istatistiksel olarak anlamlı bir fark vardır $(p=0,010)$. Birinci grupta sadece 1 restorasyonda klinik olarak kabul edilebilir düzeyde hafif madde kaybı var ilen ikinci grupta klinik olarak kabul edilebilir düzeyde hafif madde kaybı restorasyon sayısı 9'dur.

\section{TARTIŞMA}

Literatürde anterior kompozit restorasyonların takip edildiği klinik çalışmalarda retansiyon oranı $\% 53,4$ ile $\% 100$ arasında değişmektedir. ${ }^{9}$ Demirci ve ark. ${ }^{10}$ ortodontik tedavi sonrası ön bölge diastemaların restorasyonlarında direkt kompozit restorasyonları kullanmışlar ve 4 yıl sonunda Filtek Supreme XT (3M/ESPE) ile restore edilen grupta \%92,8; CeramX Duo (Dentsply) ile restore edilen grupta ise \%93 retansiyon oranı bildirmişlerdir.
Ergin ve ark. ${ }^{11}$ diastema kapatılmasında kullandıkları iki farklı kompozitin karşılaştırıldığı 4 yıllık klinik çalışmalarında retansiyon oranlarını Filtek-Z550 (3M/ ESPE)'nin kullanıldığı 1. Grupta \%96,3, CharismaDiamond (Heraeus Kulzer)'nin kullanıldığı 2. Grupta $\% 93,5$ olduğunu bildirmişlerdir. Bizim çalışmamızın 1 yıllık klinik sonuçları bu çalışmalara benzer olmakla birlikte retansiyon oranları 1. Grup için \%92,8 ve 2 . Grup için \%95,5'dir. Anterior kompozit restorasyonların takip edildiği klinik çalışmalardaki farklı retansiyon oranları hasta, diş hekimi ve diş ile ilgili faktörlere bağlı olarak değişkenlik gösterebilmektedir. Hastanın oral hijyen düzeyi, restorasyonun büyüklüğü, dişin pozisyonu, kullanılan materyalin tipi ve diş hekiminin deneyimi kompozit restorasyonların retansiyonunu etkileyen ana faktörlerdir. ${ }^{12}$ Çalışmamızda standardizasyonu sağlayabilmek amacıyla aynı hekim tarafından Clearfil Majesty $^{\mathrm{T}}{ }^{\mathrm{M}}$ ES-2 kompozit rezin kullanılarak yapılmış restorasyonlar dahil edilmiştir.

Renklenme ve yüzey pürüzlülüğü kompozit restorasyonun klinik başarısını etkileyen önemli faktörlerden biridir. Pürüzlü yüzeyleri boyayıcı partikülleri tutmasına bağlı olarak renklenme olabileceği ${ }^{13}$ gibi, pürüzlülük değeri $0,1 \mu \mathrm{m}$ değerinin altında olduğu durumlarda yüzey pürüzlülüğünün renklenmeyi etkilemediğini bildiren çalışmalar da mevcuttur. ${ }^{14} \mathrm{Bu}$ çalışmada renk uyumu ve yüzey pürüzlülüğü nedeniyle klinik olarak kabul edilemeyen, yenilenmesi gereken restorasyon bulunmamaktadır. Bizim çalışmamı, nano ve nanohibrit kompozitlerin kullanıldığı daha önceki diastema kapatılması çalışmalarıyla benzerlik göstermektedir. ${ }^{10,11}$ Kompozit rezinin yapısı, su emilimi, polimerizasyon yöntemi, yüzey sertliği, oral hijyen, bitirme ve polisaj işlemleri ve kompozit rezinin yaşı gibi bir çok faktör renk stabilitesine etki etmektedir. ${ }^{15}$ Nasim ve ark. ${ }^{16}$ kompozit restorasyonlardaki renklenmeyi minimize etmek için mükemmel polisaj tekniklerinin kullanılması gerektiğini bildirmişlerdir. Yıldırım ve ark. ${ }^{17}$ estetik restoratif materyallerin yüzey yapısını inceledikleri çalışmalarında en iyi cilalı yüzeylerin Soflex disk ve ardından cila lastikleri kullanıldığında elde edildiğini bildirmiştir. Bu çalışmada kompozit restorasyonların bitirme ve polisaj işlemlerinde ince grenli elmas frezler, alüminyum oksit kaplı diskler (Sof-Lex) ve cila lastikleri kullanılmıştır.

Literatürde de restorasyonun ağızda kalma süresi arttıkça klinik başarısızlığın arttığı gözlenmiştir. ${ }^{18}$ Kenar renklenmesi mikrosızıntının klinik belirtisidir ve mikrosızıntı restorasyonun klinik başarısını etkileyen önemli bir faktördür. ${ }^{19}$ Restoratif materyal ile kavite 
duvarı arasından bakterilerin, ağız sıvılarının ve iyonların geçişi olarak tanımlanmaktadır. ${ }^{20}$ Bu çalışmada kenar renklenmesi açısından gruplar arasında istatistiksel olarak anlamlı bir fark bulunmaktadır. Ortodontik tedavi sonrası pekiştirme apareyi kullanan hastalarda restorasyon sınırlarında polisaj ile düzeltilemeyen ciddi renklenmeler vardır. Aktif ortodontik tedavi bittikten sonra pekiştirme apereylerinin relaps riskini azaltmak için uzun süre kullanılması gerektiği bilinmektedir. ${ }^{21} \mathrm{Bu}$ apareylerin diş yüzeyleriyle uzun süre temas etmesi tükürük ve dilin temizleme etkilerinin azalması nedeniyle plak birikimine ve mine demineralizasyonuna sebep olabilmektedir. ${ }^{22}$

Pekiştirme apareyi kullanmayan hastalarda diastema kapaması için yapılmış 8 direkt kompozit restorasyonda klinik olarak kabul edilebilir hafif madde kaybı var iken 1 restorasyonda klinik olarak kabul edilemez düzeyde madde kaybı mevcuttur. Anterior dişlerde kesici kenarı içine alan kompozit restorasyonlar yüksek çiğneme kuvvetlerine maruz kaldığında kırılabilmektedirler. ${ }^{23}$ Diş gıcırdatma şikayeti olan hastalar bu çalışmaya dahil edilmemiş olsa da bireylerin diyet alışkanlıklarına bağlı olarak kompozit restorasyonlarda kırılmalar, kopmalar meydana gelebilmektedir. Ortodontik tedavi sonrası kullanılan vakumla şekillendirilen pekiştirme apareyleri polyprplylene veya polyvinyl chloride esaslıdır. ${ }^{24}$ Bu nedenle çiğneme kuvvetlerine karşı restorasyonu koruyarak kırımasını önleyerek anatomik formun devamını sağlayabilmektedir.

\section{SONUÇLAR}

Direkt kompozit restorasyonlar ön diş diastemaların tedavisinde ve maksiller lateral diş form bozukluklarında, tedavi süresinin daha kısa olması ve estetik özelliklerinin de başarılı olmaları nedeniyle hastalar tarafından tercih edilmektedir. Ortodontik tedavi sonrasında pekiştirme apareylerinin kullanılması kompozit restorasyonların anatomik formunun korunması açısından faydalı olabilmektedir. Ancak pekiştirme apareylerinin uzun süre kullanımına bağlı olarak diş yüzeylerinin tükürüğün, dilin ve dudağın temizleyici etkisinden uzak kalması kompozit- diş ara yüzünde kenar renklenmesi ve çürük oluşumuna sebep olabilmektedir. Bu nedenle direkt kompozit restorasyonlar ile diastema kapatma tedavisi yapılmış olan bireyler vakumla şekillendirilen pekiştirme apareyi kullanacak ise oral hijyene ve pekiştirme apareyinin temizliğine dikkat etmeli ve hekim kontrollerini aksatmamaya önem göstermelidir.
NOT: Çalışmada herhangi bir yazar, kurum ya da kuruluş ile çıkar çatışması içerisinde bulunmamaktadır. Makale daha önce hiçbir yerde yayınlanmamış ve yayınlanmak üzere işlem görmemektedir

\section{KAYNAKLAR}

1. Kabbach W, Sampaio C, Hirata R.(2018). Diastema closures: A novel technique to ensure dentalproportion. J Esthet Restor Dent 2018; 30: 275-80.

2. Abraham R, Kamath G. Midline diastema and its aetiology - A Review. Dent Update 2014; 41: 45764.

3. Gkantidis $\mathrm{N}$, Kolokitha $\mathrm{OE}$, Topouzelis $\mathrm{N}$. Management of maxillary midline diastema with emphasis on etiology. J Clin Pediatr Dent 2008; 32: 265-72.

4. Hwang SK, Ha JH, Jin MU. Diastema closure using direct bonding restorations combined with orthodontic treatment: a case report. Restor Dent Endod. 2012; 37: 165-9.

5. Calamia V, Pantzis A. Simple case treatment planning: diastemaclosure. Dent Clin North Am. 2015; 59: 655-64.

6. Gresnigt MM, Kalk W, Ozcan M. Randomized controlled split-mouth clinical trial of direct laminate veneers with twomicro-hybrid resin composites. J Dent 2012; 40: 766-75

7. Tüter $E$, Korkut $B$, Atalı PY, TürkmenC. Prepless Direct Midline Diastema Closure in a Single Visit: 18 months Follow-up Report. European Journal of Research in Dentistry 2019; 3: 29-34

8. Frese C, Schiller $P$, Staehle HJ, Wolff D. Recontouring teeth and closing diastemas with direct composite buildups: A 5-year follow-up. J Dent 2013; 41: 979-85

9. Demarco FF, Collares $\mathrm{K}$, Coelho-de-Souza $\mathrm{FH}$, Correa MB, Cenci MS, Moraes RR. Anterior composite restorations: A systematic review on long-term survival and reasons for failure. Dent Mater 2015; 3: 1214-24.

10. Demirci M, Tuncer S, Öztaş E, Tekçe N, Uysal Ö. A 4-year clinical evaluation of direct composite buildups for space closure after orthodontic treatment. Clin Oral Investig 2015; 19: 2187-99.

11. Ergin E, Kutuk ZB, Cakir FY, Gurgan S. Comparison of two different composite resins used for tooth reshaping and diastema closure in a 4-year followup. Niger J Clin Pract 2018; 21: 1098-106 
12. McCracken MS, Gordan VV, Litaker MS, Funkhouser E, Fellows JL, Shamp DG, Qvist V, Meral JS, Gilbert GH. A 24-month evaluation of amalgam and resin-based composite restorations. J Am Dent Assoc 2013; 144: 583-593.

13. Sarac D, Sarac YS, Kulunk S, Ural C, Kulunk T. The effect of polishing techniques on the surface roughness and color change of composite resins. J Prosthet Dent 2006; 96: 33

14. Lu H, Roeder LB, Lei L, Powers JM. Effect of surface roughness on stain resistance of dental resin composites. J Esthet Restor Dent 2005; 17: 102-8.

15. Kıvrak TÇ, Gökay O. Kompozit rezinlerin renk stabilitesine etki eden faktörler. A.Ü. Diş Hek. Fak. Derg. 2018; 45: 105-14.

16. Nasim I, Neelakantan P, Sujeer R, Subbarao CV. Color stability of microfilled, microhybrid and nanocomposite resins - An in vitro study. J Dent 2010; 38: 137-42

17. Yıldırım M, Patır A, Seymen F, Gençay K. Estetik restoratif materyallerin cila işlemlerinden sonra yüzey yapısının sem ile incelenmesi. J Dent Fac Atatürk Uni 2012; 22: 277-86.

18. Opdam NJM, Bronkhorst EM, Roeters JM, Loomans BAC. A retrospective clinical study on longevity of posterior composite and amalgam restorations. Dent Mater 2007; 23: 2-8.

19. Kidd EAM. Microleakage: a review. J Dent. 1976; 5: 199-206.

20. Sadeghi M, Lynch CD. The effect of flowable materials on the microleakage of class II composite restorations that extend apical to the cemento-enamel junction. Oper Dent. 2009; 34: 306-11

21. Shawesh M, Bhatti B, Usnami T, Nandall N. Hawley retainers full-or part-time? A randomized trial. Eur J Orthod 2010; 32: 165-70.

22. Batoni G, Pardini M, Giannotti A, Ota F, Giuca MR, Gabriele M, Campa $M$, Senesi S. Effect of removable orthodontic appliances on oral colonisation by mutans streptococci in children. Eur J Oral Sci. 2001;109: 388-92.

23. Baldissera RA, CorrêaMB, Schuch HS, Collares K, Nascimento GG, Jardim PS..Are there universal restorative composites for anterior and posterior teeth J Dent 2013; 41: 1027-35

24. Kumar AG, Bansal A. Effectiveness and acceptability of Essix and Begg retainers: A prospective study. Aust Orthod J 2011; 27: 52-6.

\section{Yazışma Adresi}

Serdar AKARSU

Restoratif Diş Tedavisi ABD, Ordu Üniversitesi Diş Hekimliği Fakültesi, Altınordu/ORDU

Tel: +904522121284

Faks: +90 4522121289

e-mail: serdarakarsu@odu.edu.tr 